\title{
Pretreatment quality of life in patients with rectal cancer is associated with intrusive thoughts and sense of coherence
}

\author{
Dan Asplund ${ }^{1}$ (D) - Thue Bisgaard ${ }^{2}$ - David Bock ${ }^{1} \cdot$ Jakob Burcharth $^{3}$. \\ Elisabeth González $^{1}$ - Eva Haglind ${ }^{1}$ - Yanislav Kolev ${ }^{4}$ Peter Matthiessen ${ }^{5}$. \\ Carina Rosander ${ }^{1}$. Jacob Rosenberg ${ }^{3} \cdot$ Kenneth Smedh $^{6}$. \\ Marina Åkerblom Sörensson ${ }^{7} \cdot$ Eva Angenete ${ }^{1}$
}

Accepted: 30 August 2017 / Published online: 14 September 2017

(C) The Author(s) 2017. This article is an open access publication

\begin{abstract}
Purpose Quality of life may predict survival. In addition to clinical variables, it may be influenced by psychological factors, some of which may be accessible for intervention. The primary objective of this study was to investigate the association of intrusive thoughts and the patients' sense of coherence with pretreatment quality of life in patients with newly diagnosed rectal cancer.

Methods Patients were prospectively included in 16 hospitals in Sweden and Denmark. They answered an extensive questionnaire after receiving their treatment plan. Clinical data were retrieved from national quality registries for rectal cancer.
\end{abstract}

Dan Asplund

dan.asplund@vgregion.se

1 Department of Surgery, Institute of Clinical Sciences, Sahlgrenska Academy, University of Gothenburg, Scandinavian Surgical Outcomes Research Group (SSORG), Sahlgrenska University Hospital/Östra, 41685 Gothenburg, Sweden

2 Department of Surgery, Hvidovre Hospital, University of Copenhagen, Copenhagen, Denmark

3 Department of Surgery, Herlev Hospital, University of Copenhagen, Copenhagen, Denmark

4 Department of Surgery, NU Hospital group, Trollhättan, Sweden

5 Department of Surgery, Faculty of Medicine and Health, Örebro University, Örebro, Sweden

6 Department of Surgery, Västmanland's Hospital Västerås, 721 89 Västerås, Sweden

7 Department of Surgery, Central Hospital of Karlstad, Karlstad, Sweden
Results Of 1248 included patients, a total of 1085 were evaluable. Pretreatment global health-related and overall quality of life was lower in patients planned for palliative compared with curative treatment (median 53 vs. 80 on the EuroQoL visual analogue scale, $p<0.001$ and odds ratio $0.56,95 \%$ confidence interval $0.36-0.88$, respectively). Quality of life was associated with intrusive thoughts (odds ratio $0.33,95 \%$ confidence interval $0.24-0.45$ ) and sense of coherence (odds ratio $0.44,95 \%$ confidence interval 0.37 0.52 ) irrespective of the treatment plan.

Conclusions Pretreatment quality of life was influenced by the intent of treatment as well as by intrusive thoughts and the patients' sense of coherence. Interventions could modify these psychological factors, and future studies should focus on initiatives to improve quality of life for this group of patients.

Keywords Cancer · Oncology · Rectal cancer · Quality of life $\cdot$ Intrusive thoughts $\cdot$ Sense of coherence $\cdot$ Clinical trial

\section{Introduction}

Rectal cancer is potentially life threatening. Curative treatment is attempted in about $80 \%$ while remaining patients receive palliative treatment [17]. Survival has improved in recent years, and consequently, quality of life (QoL) has received increasing attention [1]. Interestingly, several studies have found QoL to be predictive of survival in patients with cancer $[9,25,31]$. Furthermore, one study has demonstrated the prognostic significance of pretreatment QoL for survival in primary rectal cancer [8]. Several factors may influence pretreatment QoL in patients with newly diagnosed rectal cancer, including the cancer disease per se [12]. QoL could be influenced by the treatment plan, i.e., curative or palliative intent 
and the type of surgical procedure planned. Several studies have found QoL to be associated with psychological and personality trait variables independent of clinical factors [13, 27, 32, 33]. Cancer-related intrusive thoughts, i.e., unintentional recurrent or distressing thoughts about cancer, are among the more prominent stress-related symptoms experienced by patients with cancer $[15,30]$. An association has been reported between intrusive thoughts and QoL in patients with prostate cancer [37, 41], but this has not been studied in patients with rectal cancer. Another psychological variable that may be associated with QoL is sense of coherence (SOC), which reflects a person's view on life and capacity to respond to stressful situations $[2,10]$. Sense of coherence was developed by Aaron Antonovsky in the 1970s [2] and may be regarded as a test of personality traits or coping disposition. It mirrors the extent to which we perceive life as comprehensible, manageable, and meaningful [24]. An association between sense of coherence and quality of life has been reported in several studies [10].

We hypothesized that pretreatment quality of life is influenced by psychological factors irrespective of clinical variables like intent of treatment. The primary objective of the present analysis was to investigate the association of intrusive thoughts and the patients' sense of coherence with pretreatment quality of life in patients with newly diagnosed rectal cancer.

\section{Methods}

\section{Study design}

The QoLiRECT study is an ongoing prospective observational multicenter study of quality of life and functional outcome in patients with rectal cancer [3]. All patients aged above 18 years with a biopsy-confirmed rectal adenocarcinoma were eligible for inclusion, regardless of tumor stage or planned treatment. The only exclusion criterion was inability to understand and respond to the questionnaire due to language difficulties or to cognitive failure. Inclusion began in February 2012 and was terminated in September 2015 and took place when the diagnostic work-up was complete and the patient had been presented with a treatment plan, but before treatment had started. Informed consent was obtained from all included patients. Patients will be followed for 5 years with data collection at baseline as well as 1,2, and 5 years after inclusion. The present analysis is concerned with baseline pretreatment data only.

\section{Data collection}

At inclusion, patients completed a comprehensive pretreatment questionnaire which included questions on overall QoL and global health-related QoL, intrusive thoughts, and sense of coherence. Patients were contacted by the study secretariat by phone within a few days after inclusion and received the questionnaire by mail. In hospitals with short lead times to start of treatment, the questionnaire was handed to the patient at inclusion and was returned to the study secretariat by prepaid envelope. Questionnaires were returned to the secretariat before treatment was initiated.

At inclusion, patients were registered as candidates for either curative or palliative treatment. For curative patients, it was indicated whether the treatment plan included an abdominoperineal excision (APE) or not. This information was registered in a database at the study secretariat along with name, address, and other basic personal data needed for logistic reasons. All other clinical data, including pretreatment staging, were collected from the national quality registries (the Swedish ColoRectal Cancer Registry [26] and the national database of the Danish Colorectal Cancer Group [14]) or hospital administrative systems.

\section{Questionnaire development}

The development of the study specific questionnaire has been described in detail elsewhere [3]. The questionnaire was developed according to a well-established method $[18,36]$ including semi-structured interviews with patients followed by construction of questions and subsequent content and face-toface validation. It was forward and backward translated into Danish and then face-to-face validated once more as previously described [3]. Parts of the questionnaire have been used previously in a cross-sectional Swedish national study of patients with rectal cancer treated with abdominoperineal excision [4]. The questionnaire included novel questions specific for rectal cancer as well as questions previously used in patients with urological and gynecological cancer [6, 36, 38]. Also included was the EQ-5D-3L [7] as well as questions on cancer-related intrusive thoughts [37] and the 29-item Sense of Coherence scale (SOC-29) [2], a validated and crossculturally applicable instrument to measure sense of coherence [11].

\section{Outcome measures}

Overall QoL was assessed by the question "How would you describe your quality of life during the past month?" with a seven-point Likert scale response format anchored by zero ("No quality of life") and six ("Best possible quality of life"). Global health-related QoL was assessed by the EQ-5D-3L visual analogue scale [7,29], anchored by 0 (worst imaginable health state) and 100 (the best imaginable health state).

\section{Explanatory variables}

Cancer-related intrusive thoughts were assessed by two questions pertaining to the frequency and severity of intrusions: 
"How often during the past month have you had negative thoughts about your rectal cancer, suddenly and unintentionally?", assessed by an ordinal scale with seven levels ranging from "Never" to "More than 3 times per day or all the time," and "How intrusive have you experienced the sudden negative thoughts about your rectal cancer?", with response options "Not at all intrusive," "A little bit intrusive," "Moderately intrusive," and "Very intrusive" as well as "Not applicable." These variables were dichotomized for the analysis as explained in the corresponding tables.

Sense of coherence [2] was evaluated by SOC-29, which consists of 29 items and three domains: 11 comprehensibility items (e.g., "Do you have the feeling that you are in an unfamiliar situation and don't know what to do?"), 10 manageability items (e.g., "How often do you have feelings that you are not sure you can keep under control?"), and eight meaningfulness items (e.g., "Do you have the feeling that you don't really care about what goes on around you?"). Each item is assessed by a seven-point Likert scale, and items are summated into a total score that ranges from 29 to 203.

The third explanatory variable was the treatment plan which was either curative or palliative. Patients planned for curative treatment were further subgrouped as candidates for APE with a permanent stoma, or other curative procedures.

\section{Possible confounders}

Comorbidity was characterized by a number of health conditions, including joint disorders, cardiovascular, neurologic, pulmonary, renal, bowel and psychological conditions as well as diabetes and chronic pain, and defined as the presence of at least one of these conditions. Depression was treated as a separate confounder and was evaluated by a validated single-item question [34]. Age, sex, marital status, education, occupation, and time from diagnosis were also adjusted for in the statistical analysis as well as whether the patient considered him or herself well informed about the cancer and the planned treatment.

\section{External validity}

Selection bias was evaluated by comparing included and nonincluded patients at participating departments of surgery during the inclusion period (Fig. 1). Data were retrieved on sex, age, ASA (American Society of Anesthesiologists) grade, clinical TNM status, and tumor height from the national quality registries $[14,26]$ and hospital administrative systems.

\section{Population normative data}

A representative cohort of 3000 Swedish men and women born 1924-1983 was randomly selected from the general population through the Swedish Tax Agency and contacted by letter and telephone (Fig. 2). A total of 1078 persons (median age 63 years, range $31-90 ; 53 \%$ female) accepted to participate and completed a questionnaire similar to the study questionnaire. This allowed for comparison of results to the population norm.

\section{Statistical analysis}

A detailed statistical plan was developed prior to data analysis. A proportional odds model [22] was used to explore the association of overall QoL ("How would you describe your quality of life during the past month?") and the explanatory variables. Results were presented as odds ratios with $95 \%$ confidence intervals. A confidence interval covering one was considered non-significant. Adjusted analyses were performed with the potential confounders included as covariates. Although overall quality of life was dichotomized in Table 5 as done previously [36, 37], the odds ratios are based on the original (continuous) seven-point Likert scale. The impact of the explanatory variables on global health-related QoL (EQ-5D-3L visual analogue scale) was analyzed using Mann-Whitney test and Spearman's rank correlation.

In the calculation of the SOC-29 total sum score, missing values in $25 \%$ or less of the items were replaced by the median score for the remaining answered items. If more than $25 \%$ of
Fig. 1 Flowchart of patients. Non-included patients $(n=2242)$ did not meet the inclusion criteria or were missed to inclusion

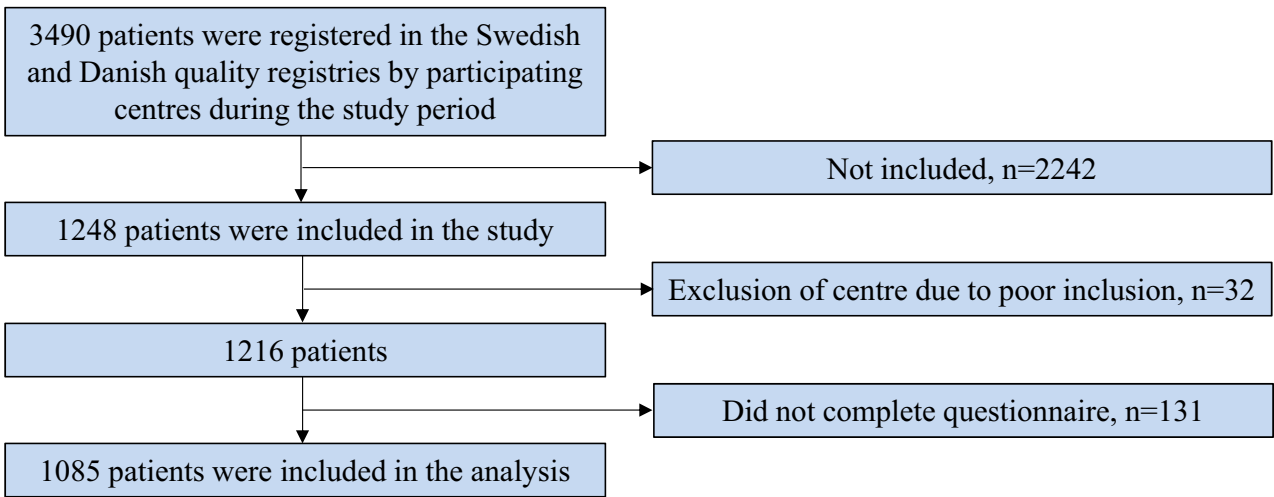


Fig. 2 Flowchart of persons included in the reference population sample

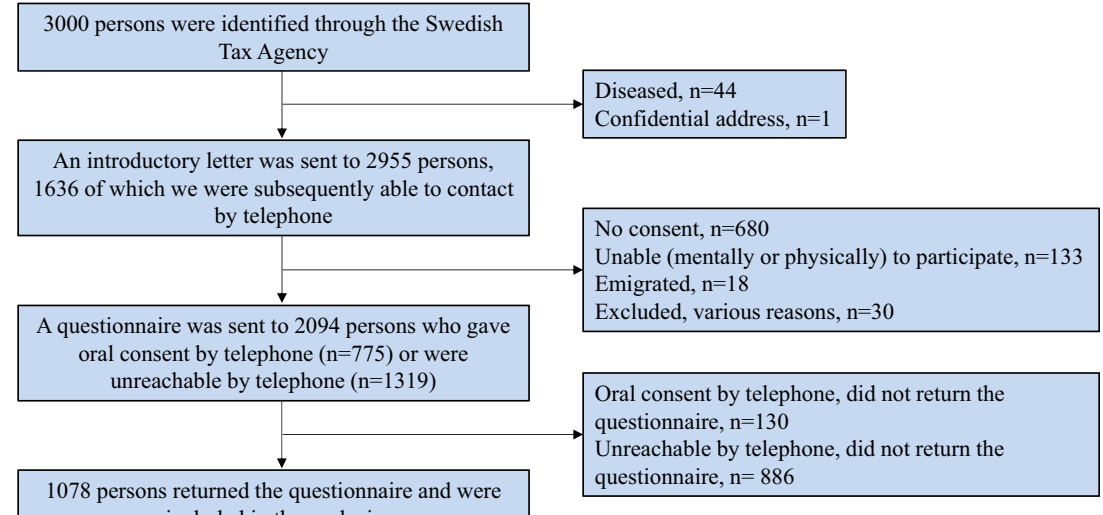
included in the analysis the items had missing values, the total score was regarded as missing.

Statistical analyses were performed using SPSS 21.0 (IBM SPSS Inc. Armonk, NY, USA) and SAS v. 9 (SAS institute).

Appropriate permission was obtained from the Danish Data Protection Agency (HEH.750.89-21; HGH-2016-016) and the Regional Ethical Review Board in Sweden (EPN 595-11) and Denmark (H-3-2012-FSP26). Permissions to use SOC-29 and EQ-5D-3L were also obtained. The study was registered at ClinicalTrials.gov (NCT01477229).

\section{Results}

Between February 2012 and September 2015, 16 departments of surgery in Sweden and Denmark prospectively included 1248 patients with newly diagnosed rectal cancer, of which 1085 patients were available for analysis (Fig. 1). There were no significant differences regarding patient demographics between patients to be treated with curative or palliative intent (Table 1) or any clinically relevant differences regarding age, sex, or tumor height between these groups (Table 2), but as
Table 1 Demography of the study group

\begin{tabular}{|c|c|c|c|c|c|}
\hline & All, $n=1085$ & Curative, $n=1012$ & Palliative, $n=73$ & $p$ value & Missing \\
\hline Marital status (\%) & & & & n.s. & 11 \\
\hline In a relationship & $796(74)$ & 747 (75) & $49(68)$ & & \\
\hline Not in a relationship & $278(26)$ & $255(25)$ & $23(32)$ & & \\
\hline Education (\%) & & & & n.s. & 19 \\
\hline University & 198 (19) & $189(19)$ & $9(13)$ & & \\
\hline No university & $868(81)$ & $806(81)$ & $62(87)$ & & \\
\hline Occupation (\%) & & & & n.s. & 17 \\
\hline Working & $311(29)$ & $292(29)$ & $19(26)$ & & \\
\hline Retired & $692(65)$ & $645(65)$ & $47(65)$ & & \\
\hline Unemployed & $14(1)$ & $14(1)$ & $0(0)$ & & \\
\hline Sick leave & $51(5)$ & $45(5)$ & $6(8)$ & & \\
\hline Comorbidity (\%) & & & & n.s. & 84 \\
\hline Yes & $661(61)$ & $610(61)$ & $51(70)$ & & \\
\hline No & $412(38)$ & $390(39)$ & $22(30)$ & & \\
\hline Depression $(\%)$ & & & & n.s. & 9 \\
\hline Yes/do not know & $181(17)$ & $165(16)$ & $16(22)$ & & \\
\hline No $(\%)$ & $895(83)$ & $839(84)$ & $56(78)$ & & \\
\hline Time since diagnosis $(\%)$ & & & & n.s. & 24 \\
\hline $0-1$ week & $165(16)$ & $152(15)$ & $13(18)$ & & \\
\hline $1-2$ weeks & $192(18)$ & $180(18)$ & $12(17)$ & & \\
\hline 2-4 weeks & $405(38)$ & 377 (38) & $28(38)$ & & \\
\hline$>4$ weeks & 299 (28) & $279(28)$ & $20(27)$ & & \\
\hline
\end{tabular}

n.s. $=p$ value $>0.05$ 
Table 2 Clinical characteristics of the study group

\begin{tabular}{|c|c|c|c|c|c|c|}
\hline & \multirow[t]{2}{*}{ All } & \multicolumn{3}{|l|}{ Curative } & \multirow[t]{2}{*}{ Palliative } & \multirow{2}{*}{$\begin{array}{l}p \\
\text { value }^{\mathrm{c}}\end{array}$} \\
\hline & & All & Not APE & APE & & \\
\hline Number of patients & 1085 & 1012 & 740 & 272 & 73 & \\
\hline $\operatorname{Sex}(\%)$ & & & & & & n.s. \\
\hline Female & $490(45)$ & $460(45)$ & $331(45)$ & $129(47)$ & $30(41)$ & \\
\hline Male & $595(55)$ & $552(55)$ & $409(55)$ & $143(53)$ & $43(59)$ & \\
\hline Age, median (range) & $69(25-100)$ & $69(25-100)$ & $68(25-100)$ & $70(38-91)$ & $70(35-96)$ & $<0.05$ \\
\hline \multicolumn{7}{|c|}{ Tumor stage, $\mathrm{cTNM}^{\mathrm{a}}(\%)$} \\
\hline $\mathrm{T} 1-\mathrm{T} 2$ & $269(25)$ & $268(26)$ & $199(27)$ & $69(25)$ & $1(1)$ & $<0.001$ \\
\hline $\mathrm{T} 3$ & $559(51)$ & $525(52)$ & $399(54)$ & $126(46)$ & $34(47)$ & \\
\hline $\mathrm{T} 4$ & $158(15)$ & $128(13)$ & $74(10)$ & $54(20)$ & $30(41)$ & \\
\hline $\mathrm{TX}$ & $99(9)$ & $91(9)$ & $68(9)$ & $23(9)$ & $8(11)$ & \\
\hline No & $426(39)$ & $416(41)$ & $306(41)$ & $110(40)$ & $10(14)$ & $<0.001$ \\
\hline $\mathrm{N} 1-\mathrm{N} 2$ & $532(49)$ & $484(48)$ & $352(48)$ & $132(49)$ & $48(66)$ & \\
\hline $\mathrm{NX}$ & $127(12)$ & $112(11)$ & $82(11)$ & $30(11)$ & $15(20)$ & \\
\hline M0 & $894(82)$ & 877 (87) & $639(87)$ & $238(87)$ & $17(23)$ & $<0.001$ \\
\hline M1 & $124(12)$ & 77 (7) & $61(8)$ & $16(6)$ & $47(64)$ & \\
\hline MX & $67(6)$ & $58(6)$ & $40(5)$ & $18(7)$ & $9(12)$ & \\
\hline $\begin{array}{l}\text { Tumor height } \mathrm{t}^{\mathrm{b}} \text {, } \\
\text { median (range) }\end{array}$ & $\begin{array}{c}8(0-15 ; \\
\text { IQR 6) }\end{array}$ & $\begin{array}{c}8(0-15 ; \\
\text { IQR 6) }\end{array}$ & $\begin{array}{r}10(0-15 ; \\
\text { IQR 4) }\end{array}$ & $\begin{array}{c}4(0-15 ; \\
\text { IQR 3) }\end{array}$ & $\begin{array}{c}9(2-15 ; \\
\text { IQR 7) }\end{array}$ & n.s. \\
\hline
\end{tabular}

n.s. $=p$ value $>0.05$

${ }^{\mathrm{a}}$ Clinical TNM stage, based on radiology

${ }^{\mathrm{b}}$ Measured in centimeters from the anal verge on retraction of a rigid rectoscope in the left lateral position. Data missing in 64 patients

${ }^{\mathrm{c}}$ Curative vs. palliative patients expected, the tumor stage differed. The distribution of sex, age, ASA grade, and clinical tumor stage differed significantly between patients included in the study and non-included patients (Table 3).

In the study group, intrusive thoughts were frequent among all patients without any significant differences between patients planned for curative and palliative treatment (Table 4). Sense of coherence differed slightly between groups (Table 4).

Patients planned for palliative treatment assessed their overall QoL and global health-related QoL as lower than patients with a curative treatment plan (Table 5). Patients with a curative treatment plan had similar global health-related QoL as a general population, but significantly lower overall QoL (data not shown). Patients planned for APE reported lower overall QoL, but not lower global health-related QoL, compared with patients planned for other types of curative treatment (Table 5). The experience of intrusive thoughts was associated with lower overall QoL and global health-related QoL. The higher the frequency and perceived intrusiveness of these thoughts, the greater was the impact on QoL (Table 5). A 25-unit increase in the total score of SOC-29 was associated with better overall QoL (odds ratio 0.44, 95\% confidence interval 0.37-0.52), and sense of coherence was positively correlated with global health-related QoL (Spearman correlation $0.44 ; p<0.001$ ).

A total of $97 \%$ of the patients planned for curative treatment considered themselves well informed about their diagnosis and treatment plan vs. $85 \%$ of the patients planned for palliative treatment, $(p<0.001)$.

\section{Discussion and conclusions}

In the present study, we found that QoL was lower in patients planned for palliative compared with curative treatment. Patients with potentially curable disease had a global healthrelated QoL comparable to that of a general population, but a significantly lower overall QoL. It is important to note that low QoL was associated with the experience of intrusive thoughts, a possibly modifiable factor. QoL was also associated with sense of coherence, a personal trait factor.

The physical effects of the disease burden as well as the psychological reaction to the palliative situation may partly explain the low QoL in patients planned for palliative treatment. One such reaction is intrusive thoughts which may be modified by expressive writing, cognitive behavioral therapy, 
Table 3 Comparison between the study group and the nonincluded patients

\begin{tabular}{|c|c|c|c|}
\hline & Study group & Non-included $^{\mathrm{a}}$ & $p$ value \\
\hline Number of patients & 1085 & 2242 & \\
\hline $\operatorname{Sex}(\%)$ & & & $<0.001$ \\
\hline Female & $490(45)$ & $882(39)$ & \\
\hline Male & $595(55)$ & $1360(61)$ & \\
\hline Age, median (range) & $69(25-100)$ & $70(23-100)$ & $<0.001$ \\
\hline ASA $\operatorname{grade}^{\mathrm{b}}(\%)$ & & & $<0.001$ \\
\hline 1 & $230(24.5)$ & $394(22)$ & \\
\hline 2 & $560(60)$ & $982(54)$ & \\
\hline 3 & $142(15)$ & $404(22)$ & \\
\hline 4 & $5(0.5)$ & $28(2)$ & \\
\hline \multicolumn{4}{|l|}{ Tumor stage, cTNM ${ }^{\mathrm{c}}(\%)$} \\
\hline $\mathrm{T} 1-\mathrm{T} 2$ & $269(25)$ & $484(22)$ & $<0.001$ \\
\hline $\mathrm{T} 3$ & $559(51)$ & $936(42)$ & \\
\hline $\mathrm{T} 4$ & $158(15)$ & $475(21)$ & \\
\hline $\mathrm{TX}$ & $99(9)$ & $347(15)$ & \\
\hline No & $426(39)$ & $420(19)$ & $<0.001$ \\
\hline $\mathrm{N} 1-\mathrm{N} 2$ & $532(49)$ & $742(33)$ & \\
\hline $\mathrm{NX}$ & $127(12)$ & $1080(48)$ & \\
\hline M0 & $894(82)$ & $1749(78)$ & $<0.001$ \\
\hline M1 & $124(12)$ & $408(18)$ & \\
\hline $\mathrm{MX}$ & $67(6)$ & $85(4)$ & \\
\hline Tumor height ${ }^{\mathrm{d}}$, median (range) & $8(0-15 ;$ IQR 6) & 8 (0-15; IQR 6) & n.s. \\
\hline
\end{tabular}

n.s. $=p$ value $>0.05$

${ }^{\text {a }}$ Patients treated at participating hospitals during the inclusion period but not included in the study

${ }^{\mathrm{b}}$ ASA (American Society of Anesthesiologists) grade is missing in patients scheduled for palliative treatment

${ }^{\mathrm{c}}$ Clinical TNM stage, based on radiology

${ }^{\mathrm{d}}$ Measured in centimeters from the anal verge on retraction of a rigid rectoscope in the left lateral position. Data were missing in 64 patients in the study group and in 55 non-included patients and pharmacological interventions [19, 23]. Although previously thought to be intrinsic and non-modifiable, recent preliminary data have indicated that sense of coherence may indeed be strengthened by psychotherapy [16].
Table 4 Distribution of psychological explanatory variables among patients planned for curative and palliative treatment

\begin{tabular}{|c|c|c|c|c|c|}
\hline & All, $n=1085$ & $\begin{array}{l}\text { Curative, } \\
n=1012\end{array}$ & Palliative, $n=73$ & $\begin{array}{l}p \\
\text { value }\end{array}$ & Missing \\
\hline $\begin{array}{l}\text { Sense of coherence, mean } \\
\quad(\mathrm{SD} \text {; range) }\end{array}$ & $158(20 ; 85-203)$ & $159(20 ; 85-203)$ & $153(22 ; 98-196)$ & $<0.05$ & 29 \\
\hline Intrusive thoughts $(\%)$ & & & & n.s. & 16 \\
\hline No & $184(17)$ & $170(17)$ & $14(19)$ & & \\
\hline Yes & $885(83)$ & $826(83)$ & $59(81)$ & & \\
\hline Frequency $(\%)$ & & & & n.s. & 16 \\
\hline Low $^{\mathrm{a}}$ & $271(31)$ & $254(31)$ & $17(29)$ & & \\
\hline $\operatorname{High}^{\mathrm{a}}$ & 614 (69) & $572(69)$ & $42(71)$ & & \\
\hline Intrusiveness (\%) & & & & n.s. & 62 \\
\hline Low $^{\mathrm{b}}$ & $551(67)$ & $516(67)$ & $35(65)$ & & \\
\hline $\operatorname{High}^{\mathrm{b}}$ & $272(33)$ & $253(33)$ & $19(35)$ & & \\
\hline
\end{tabular}

n.s. $=p$ value $>0.05$

${ }^{\text {a }}$ Less than once per week/at least once per week

${ }^{\mathrm{b}}$ Less than moderately intrusive/moderately or very intrusive 
Table 5 Association of planned treatment and intrusive thoughts with overall and global health-related QoL

\begin{tabular}{|c|c|c|c|c|c|c|c|c|}
\hline & \multicolumn{5}{|c|}{ Overall QoL } & \multicolumn{3}{|c|}{ Global health-related QoL (EQ-5D-3L VAS) } \\
\hline & Low/moderate ${ }^{\mathrm{a}}(\%)$ & $\operatorname{High}^{\mathrm{b}}(\%)$ & Comparison & $\begin{array}{l}\text { Odds } \\
\text { ratio }\end{array}$ & $95 \%$ CI & Median $(\mathrm{Q} 1 ; \mathrm{Q} 3)^{\mathrm{h}}$ & Comparison & p-value \\
\hline All patients & $733(68)$ & $339(32)$ & & & & $79(60 ; 90)$ & & \\
\hline Palliative & $61(84)$ & $12(16)$ & Curative vs. palliative & 0.56 & $0.36-0.88$ & $53(40 ; 80)$ & $\begin{array}{l}\text { Curative vs. } \\
\text { palliative }\end{array}$ & $<0.001$ \\
\hline Curative & $672(67)$ & $327(33)$ & & & & $80(60 ; 90)$ & & \\
\hline Not $\mathbf{A P E}^{\mathbf{c}}$ & $478(66)$ & $252(34)$ & Not APE vs. APE & 0.76 & $0.58-0.99$ & $80(62 ; 90)$ & Not APE vs. APE & 0.080 \\
\hline $\mathbf{A P E}^{\mathrm{d}}$ & $194(72)$ & $75(28)$ & & & & $75(60 ; 90)$ & & \\
\hline \multicolumn{9}{|c|}{ Intrusive thoughts } \\
\hline No & $76(42)$ & $103(58)$ & No vs. yes & 0.33 & $0.24-0.45$ & $85(75 ; 90)$ & No vs. yes & $<0.001$ \\
\hline Yes & $646(74)$ & $232(26)$ & & & & $75(60 ; 88)$ & & \\
\hline \multicolumn{9}{|l|}{ Frequency } \\
\hline Low $^{e}$ & $157(58)$ & $113(42)$ & $\begin{array}{l}\text { Low vs. high } \\
\text { frequency }\end{array}$ & 0.43 & $0.32-0.57$ & $80(70 ; 90)$ & $\begin{array}{l}\text { Low vs. high } \\
\text { frequency }\end{array}$ & $<0.001$ \\
\hline High $^{\mathrm{e}}$ & $489(80)$ & $119(20)$ & & & & $70(50 ; 82)$ & & \\
\hline \multicolumn{9}{|c|}{ Intrusiveness } \\
\hline Low $^{f}$ & $368(67)$ & $178(33)$ & $\begin{array}{l}\text { Low vs. high } \\
\text { intrusiveness }\end{array}$ & 0.38 & $0.29-0.52$ & $80(61 ; 90)$ & $\begin{array}{l}\text { Low vs. high } \\
\text { intrusiveness }\end{array}$ & $<0.001$ \\
\hline $\operatorname{High}^{f}$ & $235(86)$ & $37(14)$ & & & & $69(50 ; 80)$ & & \\
\hline
\end{tabular}

Overall QoL is presented here as a dichotomized outcome (blue left columns), but the odds ratios for the comparisons between subgroups (pink left columns) are based on the original seven-point Likert scale

${ }^{\text {a }}$ Zero to four on a seven-point Likert scale

${ }^{\mathrm{b}}$ Five to six on a seven-point Likert scale

${ }^{\mathrm{c}}$ Patients operated by other curative procedures than abdominoperineal excision

${ }^{\mathrm{d}}$ Patients operated by abdominoperineal excision

${ }^{\mathrm{e}}$ Less than once per week/at least once per week

${ }^{\mathrm{f}}$ Less than moderately intrusive/moderately or very intrusive

${ }^{\mathrm{g}}$ Odds ratio for a lower overall QoL, adjusted for age, sex, comorbidity, depression, occupation, education, marital status, sense of coherence, time from diagnosis, and whether the patient regarded him or herself well informed about the cancer and planned treatment

${ }^{\mathrm{h}}$ Data missing in 87 patients

There were no clinically relevant differences of overall QoL or global health-related QoL between patients planned for curative treatment with APE vs. other curative procedures [29]. In view of the fact that $97 \%$ of the curative patients felt well informed about their treatment, this indicates that patients received adequate supportive care when presented with their treatment plan, including patients scheduled for a permanent stoma. As recently reported, Swedish patients' QoL was not limited by the presence of a permanent stoma following APE for rectal cancer [21].

A lower percentage of patients planned for palliative treatment considered themselves well informed about their diagnosis and treatment plan compared with patients planned for curative treatment. This indicates a need for improved communication of palliative treatment, perhaps in a more structured manner $[28,40]$. In this context, better support for the surgeon may ultimately improve patient outcome [5].

QoL was assessed by two global single questions pertaining to "overall" and "health-related" QoL, respectively. While the latter question concerns the patients' self-rated health state, the question on overall QoL relates also to other aspects of life that may affect QoL. In view of this, it is interesting that patients with a potentially curable disease differed from a normal population with regard to overall but not global health-related
QoL, meaning that their "health state" was not impaired by the cancer but their general perception of QoL was.

Strengths of this study include the large patient cohort and the inclusion of patients regardless of tumor stage. The participation of university as well as county hospitals increases the generalizability of results. Study hypotheses and a detailed statistical analysis plan were decided on prior to data analyses. The questionnaire was developed in a systematic way using prevalidated questions as well as newly constructed diseasespecific questions validated according to accepted principles $[3,6,18,36,37]$. The patients completed the questionnaire at home and returned it to the coordinating center and not to the treating hospital which may minimize bias [20].

Missing data were generally low. However, for global health-related QoL, missing and/or invalid values were more frequent, which we found to be partly explained by difficulties for patients to correctly interpret instructions on how to fill out their response on the EQ-5D-3L visual analogue scale. This may potentially bias the results, but the direction and significance of this bias are unclear.

Women were overrepresented among included compared to non-included patients, but the sex distribution in the study group was comparable to that reported for all new cases of colorectal cancer in Europe 2012 [39]. Median age differed 
significantly between included and non-included patients, but the 1-year difference is hardly of any clinical relevance in relation to QoL. Included patients had a significantly lower ASA grade, indicating that they were somewhat healthier than non-included patients. Clinical tumor stage was significantly lower in the study group. The differences in ASA grade and clinical tumor stage between included and non-included patients must be considered in relation to the generalizability of results, although the clinical relevance of the rather small differences is difficult to determine.

A good understanding of Swedish or Danish was required for participation, and thus, the results are not valid for patients with little or no knowledge of these languages. Another limitation of the study is that we did not have detailed information on how the treatment plan was communicated to patients. However, many participating departments of surgery and caregivers may reduce the influence of differences in communication and may reflect real life clinical practice at the time.

Although efforts were made to recruit palliative patients to the study, they seem somewhat underrepresented. However, the classification of patients as curative or palliative was done prospectively at the time of inclusion. As some patients initially scheduled for curative treatment were not operated, the number of missed palliative patients may actually not be as large as it looks. If a selection bias is present with regard to patients planned for palliative treatment, it may lead to an overestimation of QoL in this group.

Our results indicate that psychological factors need to be considered as confounders in clinical studies that aim to describe quality of life. Furthermore, reducing intrusive thoughts by way of a simple intervention like expressive writing [23] may offer patients relief and possibly improve quality of life in the face of a rectal cancer diagnosis.

The reported association of QoL and survival in patients with cancer in general $[9,25,31]$, and of pretreatment QoL and survival in primary rectal cancer in particular [8], underpins the importance of our results. Furthermore, a survival benefit of psychosocial intervention in patients with cancer has been suggested [35]. However, whether efforts to improve pretreatment QoL will translate into a better survival in patients with rectal cancer remains to be demonstrated.

We conclude that the QoL of Scandinavian patients who had just received the treatment plan for their newly diagnosed rectal cancer may be influenced by the presence of intrusive thoughts and the patients' sense of coherence as well as of the intent of treatment. Future studies should evaluate the effect of interventions aimed to improve QoL.

Acknowledgements The authors gratefully acknowledge the excellent work performed by the research nurses at the Scandinavian Surgical Outcomes Research Group and by all those involved in the recruitment of patients at participating hospitals: Sahlgrenska University Hospital/
Östra; Skaraborg Hospital Skövde; NU Hospital Group, Trollhättan; Central Hospital of Karlstad; Södra Älvsborg Hospital, Borås; Karolinska University Hospital; Örebro University Hospital; Sunderbyn Hospital; Västmanland's Hospital Västerås, Blekinge Hospital, Karlskrona; Mora Hospital; Helsingborg Hospital; Hvidovre Hospital; Slagelse Hospital; Herlev Hospital; and Roskilde Hospital.

Author contribution All authors have fulfilled the Uniform Requirements for Manuscripts Submitted to Biomedical Journals statement of the International Committee of Medical Journal Editors.

Funding The Swedish Research Council, grant number 2012-1768; the Swedish Cancer Society CAN 2013/500; the Swedish Society of Medicine; the Gothenburg Medical Society; the Healthcare subcommittee, Region Västra Götaland; ALF grant ALFGBG-526501, ALFGBG136151, and ALFGBG-493341, "Agreement concerning research and education of doctors"; Anna-Lisa and Bror Björnsson Foundation; Assar Gabrielsson Foundation; Mary von Sydow Foundation; Ruth and Richard Julin's Foundation; Lion's Cancer Research Foundation of Western Sweden.

\section{Compliance with ethical standards}

ClinicalTrials.gov Identifier NCT01477229

Previous communication None.

Conflict of interest The authors declare that they have no conflict of interest.

Open Access This article is distributed under the terms of the Creative Commons Attribution 4.0 International License (http:// creativecommons.org/licenses/by/4.0/), which permits unrestricted use, distribution, and reproduction in any medium, provided you give appropriate credit to the original author(s) and the source, provide a link to the Creative Commons license, and indicate if changes were made.

\section{References}

1. Andersson J, Angenete E, Gellerstedt M et al (2013) Health-related quality of life after laparoscopic and open surgery for rectal cancer in a randomized trial. Br J Surg 100:941-949

2. Antonovsky A (1993) The structure and properties of the sense of coherence scale. Social Sci Med (1982) 36:725-733

3. Asplund D, Heath J, Gonzalez E et al (2014) Self-reported quality of life and functional outcome in patients with rectal cancerQoLiRECT. Dan Med J 61:A4841

4. Asplund D, Prytz M, Bock D et al (2015) Persistent perineal morbidity is common following abdominoperineal excision for rectal cancer. Int J Color Dis 30:1563-1570

5. Balogh EP, Ganz PA, Murphy SB et al (2011) Patient-centered cancer treatment planning: improving the quality of oncology care. Summary of an Institute of Medicine workshop. Oncologist 16: 1800-1805

6. Bergmark K, Avall-Lundqvist E, Dickman PW et al (1999) Vaginal changes and sexuality in women with a history of cervical cancer. $\mathrm{N}$ Engl J Med 340:1383-1389

7. Brooks R (1996) EuroQol: the current state of play. Health Policy (Amsterdam, Netherlands) 37:53-72 
8. Camilleri-Brennan J, Steele R (2001) Prospective analysis of quality of life and survival following mesorectal excision for rectal cancer. Br J Surg 88:1617-1622

9. Efficace F, Innominato PF, Bjarnason G et al (2008) Validation of patient's self-reported social functioning as an independent prognostic factor for survival in metastatic colorectal cancer patients: results of an international study by the Chronotherapy Group of the European Organisation for Research and Treatment of Cancer. J Clin Oncol Off J Am Soc Clin Oncol 26:2020-2026

10. Eriksson M, Lindstrom B (2007) Antonovsky's sense of coherence scale and its relation with quality of life: a systematic review. J Epidemiol Community Health 61:938-944

11. Eriksson M, Lindstrom B (2005) Validity of Antonovsky's sense of coherence scale: a systematic review. J Epidemiol Community Health 59:460-466

12. Gray NM, Hall SJ, Browne S et al (2011) Modifiable and fixed factors predicting quality of life in people with colorectal cancer. Br J Cancer 104:1697-1703

13. Hyphantis T, Paika V, Almyroudi A et al (2011) Personality variables as predictors of early non-metastatic colorectal cancer patients' psychological distress and health-related quality of life: a one-year prospective study. J Psychosom Res 70:411-421

14. Iversen LH, Green A, Ingeholm P et al (2016) Improved survival of colorectal cancer in Denmark during 2001-2012 - the efforts of several national initiatives. Acta Oncol (Stockholm, Sweden) 55(Suppl 2):10-23

15. Jim HS, Jacobsen PB (2008) Posttraumatic stress and posttraumatic growth in cancer survivorship: a review. Cancer J (Sudbury, Mass) 14:414-419

16. Kahonen K, Naatanen P, Tolvanen A et al (2012) Development of sense of coherence during two group interventions. Scand J Psychol 53:523-527

17. Kodeda K, Johansson R, Zar N et al (2015) Time trends, improvements and national auditing of rectal cancer management over an 18-year period. Color Dis: Offl J Assocf Coloproctol Great Br Irel 17:O168-O179

18. Kreicbergs U, Valdimarsdottir U, Onelov E et al (2004) Talking about death with children who have severe malignant disease. $\mathrm{N}$ Engl J Med 351:1175-1186

19. Lindgren ME, Fagundes CP, Alfano CM et al (2013) Beta-blockers may reduce intrusive thoughts in newly diagnosed cancer patients. Psycho-Oncology 22:1889-1894

20. Mansson A, Henningsohn L, Steineck G et al (2004) Neutral third party versus treating institution for evaluating quality of life after radical cystectomy. Eur Urol 46:195-199

21. Marinez AC, Gonzalez E, Holm K et al (2016) Stoma-related symptoms in patients operated for rectal cancer with abdominoperineal excision. Int J Color Dis 31:635-641

22. Mcculllagh P, Nelder J (1989) A generalized linear models. Chapman \& Hall

23. Merz EL, Fox RS, Malcarne VL (2014) Expressive writing interventions in cancer patients: a systematic review. Health Psychol Rev 8:339-361

24. Mittelmark M, Sagy S, Eriksson M et al. (2016) The handbook of salutogenesis. Springer http://link.springer.com/book/10.1007/9783-319-04600-6
25. Montazeri A (2009) Quality of life data as prognostic indicators of survival in cancer patients: an overview of the literature from 1982 to 2008. Health Qual Life Outcomes 7:102

26. Pahlman L, Bohe M, Cedermark B et al (2007) The Swedish rectal cancer registry. Br J Surg 94:1285-1292

27. Paika V, Almyroudi A, Tomenson B et al (2010) Personality variables are associated with colorectal cancer patients' quality of life independent of psychological distress and disease severity. PsychoOncology 19:273-282

28. Peppercorn JM, Smith TJ, Helft PR et al (2011) American society of clinical oncology statement: toward individualized care for patients with advanced cancer. J Clin Oncol Off J Am Soc Clin Oncol 29:755-760

29. Pickard AS, Neary MP, Cella D (2007) Estimation of minimally important differences in EQ-5D utility and VAS scores in cancer. Health Qual Life Outcomes 5:70

30. Primo K, Compas BE, Oppedisano G et al (2000) Intrusive thoughts and avoidance in breast cancer: individual differences and association with psychological distress. Psychol Health 14: $1141-1153$

31. Quinten C, Coens C, Mauer M et al (2009) Baseline quality of life as a prognostic indicator of survival: a meta-analysis of individual patient data from EORTC clinical trials. Lancet Oncol 10:865-871

32. Sales PM, Carvalho AF, Mcintyre RS et al (2014) Psychosocial predictors of health outcomes in colorectal cancer: a comprehensive review. Cancer Treat Rev 40:800-809

33. Siassi M, Weiss M, Hohenberger W et al (2009) Personality rather than clinical variables determines quality of life after major colorectal surgery. Dis Colon Rectum 52:662-668

34. Skoogh J, Ylitalo N, Larsson Omerov P et al (2010) 'A no means no'-measuring depression using a single-item question versus Hospital Anxiety and Depression Scale (HADS-D). Ann Oncol: Off J Eur Soc Med Oncol/ESMO 21:1905-1909

35. Spiegel D, Bloom JR, Kraemer HC et al (1989) Effect of psychosocial treatment on survival of patients with metastatic breast cancer. Lancet 2:888-891

36. Steineck G, Helgesen F, Adolfsson J et al (2002) Quality of life after radical prostatectomy or watchful waiting. N Engl J Med 347:790 796

37. Thorsteinsdottir T, Hedelin M, Stranne J et al (2013) Intrusive thoughts and quality of life among men with prostate cancer before and three months after surgery. Health Qual Life Outcomes 11:154

38. Thorsteinsdottir T, Stranne J, Carlsson S et al (2011) LAPPRO: a prospective multicentre comparative study of robot-assisted laparoscopic and retropubic radical prostatectomy for prostate cancer. Scand J Urol Nephrol 45:102-112

39. Valentini V, Glimelius B, Haustermans K et al (2014) EURECCA consensus conference highlights about rectal cancer clinical management: the radiation oncologist's expert review. Radiother Oncol: J Eur Soc Ther Radiol Oncol 110:195-198

40. Weeks JC, Catalano PJ, Cronin A et al (2012) Patients' expectations about effects of chemotherapy for advanced cancer. N Engl J Med 367:1616-1625

41. Whitaker KL, Brewin CR, Watson M (2008) Intrusive cognitions and anxiety in cancer patients. J Psychosom Res 64:509-517 